\title{
A TRAJETÓRIA HISTÓRICA DA LIBERDADE DE EXPRESSÃO: SUA IMPORTÂNCIA PARA A LEGITIMIDADE DA DEMOCRACIA
}

\author{
Bianca Tito* \\ Bibiana Terra*
}

Resumo: A presente pesquisa tem como objetivo analisar a história da liberdade de expressão, tendo em vista a importância que hoje essa possui para a legitimação e manutenção do Estado Democrático de Direito. Para tanto, são delineados os principais autores e momentos que foram os responsáveis para que essa se consolidasse como um direito fundamental assegurado para todos os cidadãos. O trabalho aborda aspectos de cunho histórico, com alguns dos mais importantes teóricos a se dedicarem ao tema, e de cunho jurídico, com os documentos internacionais que preveem essa garantia.

Palavras-chave: Liberdade de expressão; Democracia; Dignidade da pessoa humana; Estado constitucional; Direitos fundamentais; História do Direito.

\section{THE HISTORICAL TRAJECTORY OF FREE SPEECH: ITS IMPORTANCE TO THE LEGITIMITY OF DEMOCRACY}

\begin{abstract}
This research aims to analyze the history of free speech, in view of the importance it has today for the legitimization and maintenance of the Democratic Rule of Law. Therefore, the main authors and moments that were responsible for this consolidation as a fundamental right guaranteed to all citizens are outlined. The work addresses aspects of a historical nature, with some of the most important theorists that have dedicated to the theme, and for a legal nature, with international documents that provide for this guarantee.
\end{abstract}

Keywords: Free speech; Democracy; Dignity of human person; Constitutional state; Fundamental rights; History of Law.

\section{Introdução}

No último século o direito à liberdade de expressão se consagrou como a base das democracias modernas, o que significa que se esse direito não restar garantido pelos ordenamentos jurídicos dos países democráticos, então, por consequência, não será possível que esses se determinem como Estados de Direito. Até mesmo porque quando ausente a garantia aos cidadãos para que se manifestem livremente o que há é a censura, a qual é

\footnotetext{
* Mestra em Direito pela Faculdade de Direito do Sul de Minas (FDSM). Graduada em Direito pela PUC Minas. Pesquisadora e advogada. E-mail: biancaberaldo_tito@ outlook.com.

* Mestra em Direito pela Faculdade de Direito do Sul de Minas (FDSM). Graduada em Direito pela PUC Minas. Pesquisadora e advogada. E-mail: bibianaterra@yahoo.com.
} 
incompatível com esse regime político. Logo, democracia e liberdade de expressão são conceitos que se encontram conectados.

No entanto, essa interpretação é fruto de um longo processo histórico, do qual diversos autores, influenciados por diferentes fatores, fizeram parte e, não obstante as divergências que podem ser apontadas entre eles, contribuíram para que a liberdade de expressão passasse a ser compreendida como direito fundamental a ser estendido para todos os cidadãos, sem diferenciações de qualquer natureza. Tal construção pode ser observada tanto pelas teorias da liberdade de expressão que foram desenvolvidas, como também pela sua consolidação legislativa e jurisprudencial.

Nesse cenário, a presente pesquisa tem como objetivo analisar a história da liberdade de expressão, tendo em vista a importância que hoje essa possui para a legitimação e manutenção do Estado Democrático de Direito, delineando os principais autores e momentos que foram os responsáveis para que assim essa se consolidasse. Com isso, dada a extensa produção bibliográfica existente acerca do tema, torna-se inviável uma reconstrução histórica que delineie sobre todos eles, mas, ainda assim, diante do objetivo proposto, é possível que, conforme apontado, nos detenhamos sobre aqueles que foram os responsáveis pela compreensão que hoje se tem desse direito.

Para tanto, através de uma pesquisa de caráter descritivo e explicativo, é adotada como metodologia a pesquisa bibliográfica. Utilizando de materiais que se encontram previamente elaborados, essa se dará principalmente a partir de livros e artigos científicos de publicação periódica, os quais serão fontes que permitem uma abordagem teórica do tema. Ainda, há também uma pesquisa documental, apoiada em legislação e jurisprudência pertinentes a investigação proposta, dado que procurando a construção de uma perspectiva histórica da liberdade de expressão, essas são perspectivas que não podem ser ignoradas.

Uma pesquisa como essa revela-se extremamente importante, não só pela relevância que é inerente aos estudos sobre a liberdade de expressão, mas porque no cenário mundial atual esse é um tema sobre o qual é urgente discutirmos. Com isso em vista, compreender a trajetória histórica da liberdade de expressão contribui para que possamos discutir o papel que hoje ela ocupa dentro das democracias.

\section{O princípio da tolerância como origem da liberdade de expressão}


Quando nos referimos a trajetória histórica do direito à liberdade de expressão é importante tomarmos como ponto de partida as discussões sobre o princípio da tolerância, pois que são nessas que residem as suas raízes, existindo, assim, uma ligação histórica entre tais conceitos. Foi com os autores que se dedicaram a questão da tolerância que teve início a construção de um pensamento que, no futuro, em uma sociedade moderna ${ }^{3}$, se transformaria na defesa pela liberdade de expressão dos cidadãos (TITO, 2021).

Isso significa que é a partir dessa, com o pluralismo de ideias e a heterogeneidade de valores que lhe são característicos, que o problema da intolerância de fato surge e recebe atenção. Em relação a isso:

É justamente a inexistência de uma única forma de vida considerada mais elevada que as demais que será a marca da sociedade moderna e, posteriormente e com mais contundência, das sociedades complexas contemporâneas. O pluralismo de valores, de práticas e de ideias alçará a virtude da tolerância, a pedra de toque da organização da sociedade (MEDRADO, 2019, p. 17).

Com isso, observa-se que a existência de diferentes concepções de vida e de ideias fez com que a tolerância se tornasse necessária, o que ocorre tendo em vista uma importante mudança advinda das sociedades modernas, isso é, de uma transição ocorrida do mundo antigo para o moderno, qual seja: o indivíduo, enquanto sujeito, passa a ser o centro de suas próprias ações. Algo que não existia na Antiguidade ou na Idade Média, em que havia um único centro como o orientador de toda a ação, significando um modo correto de agir, que estivesse em conformidade as regras, princípios e valores deste centro (GALUPPO, 2004).

Dessa maneira, é possível notarmos que "a grande novidade moderna é o surgimento da ideia de sujeito e de indivíduo com existência independente da totalidade em que está inserido" (MEDRADO, 2019, p. 19). Algo que, como notaremos, não só contribuirá para que haja uma necessidade de tolerância entre sujeitos distintos, que precisam coexistir em um novo cenário marcadamente plural, mas fará com que surjam argumentações em defesa da liberdade desses para que coloquem em prática os seus planos de vida, o que se revelou fundamental para que posteriormente viesse a ser desenvolvido o Estado Democrático de Direito.

É, então, o surgimento do indivíduo moderno o fator responsável pela desconstrução da ideia até então prevalente de que a sociedade seria composta por grupos homogêneos. "Ao

\footnotetext{
${ }^{3}$ As obras sobre esse princípio foram escritas na modernidade, dado que na Antiguidade e Idade Média não se escrevia sobre isso, pois que o problema da tolerância não foi vivenciado pelas comunidades antigas da forma como é vivenciado no mundo moderno. Foi a partir dos conflitos entre católicos e protestantes, já no séc. XVI, que de fato o uso da palavra tolerância se consolidou no vocabulário filosófico e político (GALUPPO, 2004).
} 
contrário, as sociedades modernas se caracterizam exatamente pela diferença, pelo fato de que as pessoas não mais comungam dos mesmos valores e ideias" (MEDRADO, 2019, p. 21). E, nesse cenário, destacam-se dois importantes textos sobre a tolerância que, devido as interpretações que apresentam, representam uma reflexão sobre a necessidade de que o poder estatal não fosse exercido de modo ilimitado e que as liberdades básicas restassem garantidas (TITO, 2021).

São esses: no séc. XVII, a Carta sobre a Tolerância, de John Locke (2019), e, no século seguinte, o Tratado Sobre a Tolerância, de Voltaire (2017), ambos bastante marcados pelo ideal de tolerância religiosa, assunto de grandes discussões naquele momento. No primeiro deles, a Carta de Locke destaca que a prática da tolerância para com aqueles que possuem, nos assuntos religiosos, opiniões distintas é algo que está sim de acordo com aquilo que o Evangelho de Jesus Cristo prega. Está também de acordo com a razão humana, o que demonstra como o pensamento de Locke está inserido nesse novo mundo ainda em formação. Por isso, lhe parecia monstruoso que houvesse homens que não enxergassem isso e não percebessem a vantagem e necessidade de agirem com tolerância (LOCKE, 2019).

O filósofo inglês condenava que os magistrados fossem utilizados como um mecanismo para compelir os cidadãos a acreditarem em algo que, em realidade, eles não acreditam. Ou seja, que o poder estatal fosse utilizado com o intuito de converter os indivíduos em uma crença que, se não fosse por tal imposição, eles não acreditariam e da qual, se pudessem, não fariam parte. Ele defendia a utilização da razão e que somente essa seria capaz de conceber uma verdadeira mudança no pensamento das pessoas, diferentemente do uso da força, em que essa não está de acordo com os ideais de amor, caridade e boa vontade que devem guiar aqueles que fazem parte de uma Igreja Cristã (LOCKE, 2019).

Nota-se com isso, ainda que em estágios bastante iniciais, a formação de um argumento hoje considerado extremamente importante nas discussões sobre a liberdade de expressão, que é o de que os princípios morais dos indivíduos devem ser tomados em consideração, evitando obrigá-los a acreditarem em algo porque assim deseja uma maioria, ignorando que eles possuam as suas próprias razões para crerem ou não em alguma doutrina (à época é evidente que o que interessava Locke era a questão religiosa, mas esse é um argumento que hoje se faz relevante em relação aos mais diversos assuntos) (TITO, 2021).

Esse autor se dedicou a defender uma ideia segundo qual "a tolerância religiosa e a separação entre religião e Estado poderiam ser deduzidas do próprio Texto Sagrado" 
(MEDRADO, 2019, p. 26). E, dessa maneira, para Locke, o respeito as demais formas de culto é algo que, diferentemente do que pareciam pensar outros homens de sua época, estaria em concordância com aquilo que a Igreja prega e ensina aos seus adeptos. Isso não significa que ele não acreditasse que as pessoas podem ser convertidas, ou seja, convencidas a mudarem as suas crenças, mas sim que isso deveria ser feito pela razão e não pelo "ferro e fogo" (LOCKE, 2019, p. 8).

Em sua Carta ele aponta que aqueles que assim o fazem, usando da força como um método de convencimento, estão na verdade é tentando reunir em assembleia um grande número de pessoas que pensem igual, e não instituindo uma Igreja cristã. Por isso que ele não compreendia como razoável a justificativa de que alguns homens deveriam, alegadamente, ser incumbidos do papel de salvar os demais, pois que um argumento como esse não o convencia, já que entendia que essa salvação serviria apenas como uma espécie de desculpa daqueles que, disfarçados de cristãos, preferem fazer uso da força do que da razão para mudar o pensamento dos demais (TITO, 2021).

Assim, nas palavras do autor:

Confesso que o fato de alguém julgar apropriado levar outro homem, cuja salvação
deseja de todo o coração, a sofrer tormentos, mesmo ainda não se tendo convertido,
sempre me parecerá surpreendente e, creio, a toda outra pessoa. Mas certamente
ninguém vai acreditar que essa atitude tenha nascido da caridade, do amor ou da boa
vontade. Se alguém sustentar que os homens devem ser compelidos a ferro e fogo a
professar certas doutrinas, e a adotar essa ou aquela forma de culto exterior, sem
contudo levar em consideração seus princípios morais; se alguém tentar converter à
sua fé aqueles que laboram no erro, obrigando-os a cultuar coisas nas quais não
acreditam e permitindo-lhes praticar coisas que o Evangelho não permite - não
duvido nem um pouco de que este apenas deseja reunir em uma numerosa
assembleia adeptos de sua confissão, sendo, contudo, absolutamente impossível crer
que pretenda instituir uma Igreja Cristã (LOCKE, 2019, p. 8).

Observa-se que Locke (2019) está preocupado com um uso ilegítimo da força, entendendo que a razão seria o melhor caminho. Por isso, em seu texto, é possível notarmos que a comunidade "é fruto de um pacto entre pessoas livres para proteção da vida, da liberdade e da propriedade umas das outras e do inimigo externo. O poder e o dever do magistrado, portanto, restringem-se aos assuntos civis e não podem ser estendidos para a salvação da alma" (MEDRADO, 2019, p. 27).

De toda a sua Carta, o argumento mais importante trazido pelo filósofo inglês, que pode ser encontrado em outros autores mais recentes e que, três séculos depois, continua a influenciar as discussões sobre a liberdade de expressão, é o de que a censura é insuficiente para mudar aquilo que as pessoas pensam e acreditam. Essa pode até fazer com elas alterem 
seus posicionamentos, mas não será uma mudança real, que, nas palavras de Locke (2019, p. 11) é uma mudança da mente. Os bens materiais podem ser confiscados, penas podem ser aplicadas e homens aprisionados, mas essas são práticas que só podem ser exercidas sob o corpo dos homens, mas não em suas mentes e pensamentos.

À vista disso, ele é considerado o "responsável por teorizar a urgente necessidade de combate à intolerância religiosa" (TITO, 2021, p. 203-204), tendo se dedicado a apresentar soluções para esse que é o grande desafio da modernidade. Por isso, admitindo que embora muitas sejam as questões envolvem o tema da religião, há uma que Locke (2019) acreditava ser indubitável, que é a afirmação de que crença nenhuma poderia ser útil para alguém se a pessoa não acreditasse verdadeiramente nela. Sendo inútil o magistrado compeli-las a crerem no que quer que seja, ainda que sob o pretexto de salvar suas almas, pois é muito mais benéfico deixá-los decidirem, por sua própria vontade, sobre aquilo em que acreditam. "Logo, deve-se, em última análise, deixá-los à sua própria consciência” (LOCKE, 2019, p. 32). Em síntese:

\begin{abstract}
Mesmo que a opinião do magistrado em religião seja fundamentada e mesmo que o caminho que aponte seja verdadeiramente evangélico, se eu não estiver profundamente convicto disso em meu próprio espírito, não haverá garantia em seu seguimento. Nenhum caminho que eu trilhe contra os ditames de minha consciência jamais me levará às mansões dos abençoados. Posso enriquecer através de um ofício que não me agrada, posso ser curado de uma moléstia por um remédio no qual não confio, mas não posso ser salvo mediante uma religião na qual não confio, ou um culto que não me agrada. É inútil que um descrente assuma as manifestações externas da profissão de outro homem. Somente a fé e a sinceridade interior constituem coisas que agradam a Deus (LOCKE, 2019, p. 31).
\end{abstract}

É nítido o caráter religioso presente no texto de Locke, não obstante, ele serve para demonstrar uma importante defesa pelo uso da razão e que a censura seja evitada, dada sua inutilidade em mudar o pensamento alheio. Uma compreensão como essa, juntamente ao Tratado Sobre a Tolerância, escrito por Voltaire (2017) no século seguinte, se constituem em dois dos mais importantes textos a revelarem a indispensabilidade do princípio da tolerância para as sociedades pluralistas. Ambos perceberam que esse princípio "era imprescindível para a coordenação das diversas crenças e das diversas concepções de bem que surgiam naquele momento" (ASSAF, 2019, p. 23).

Assim, conforme vem sendo destacado pela pesquisa, e tendo em vista nosso objetivo, nota-se que "o tratamento dado por esses filósofos ao tema foi importante não só para a afirmação do direito à liberdade de culto e consciência, mas porque em seu fundamento já estava contido o germe da liberdade de expressão" (ASSAF, 2019, p. 23). Em relação a 
Voltaire (2017), o filósofo francês, assim como Locke, também se viu influenciado pelo ambiente no qual estava inserido, marcado pela intolerância e perseguições religiosas, em que as consequências dessas o levaram a se dedicar ao tema da tolerância, notadamente a tolerância religiosa.

No século XVII ocorreu na França, na cidade de Toulouse, tradicionalmente católica, a condenação à morte de um homem protestante. Esse, Jean Calas, era um pai de família que foi acusado de matar seu filho por motivos religiosos, ainda, os demais membros da família também foram acusados e presos como cúmplices do crime. Isso se deu em razão do suicídio de Marco Antônio, tendo a sociedade acusado Jean Calas de matá-lo estrangulado por não aceitar sua religião. Porém, como acabou sendo provado posteriormente, o filho que havia se suicidado devido a razões de intolerância religiosa (VOLTAIRE, 2017).

Desejando tornar-se advogado, esse dependia da expedição de certificados de catolicidade, no entanto não os conseguiu e, frustrado com isso, decidiu por tirar a própria vida. E, diante de tal evento, uma sociedade religiosamente fanática acusou Jean Calas de matar Marco Antônio, tendo tal fanatismo levado os juízes a condenarem o pai ao suplício da roda (instrumento de tortura à época utilizado para executar penas de morte, quebrando os ossos do condenado) (VOLTAIRE, 2017).

Isso chamou a atenção de Voltaire e se tornou seu objeto de estudo, pois o filósofo percebeu a ironia que envolvia os fatos, vez que aquela mesma intolerância religiosa que levou Marco Antônio a decidir por tirar a própria vida, fez com que os seus familiares fossem juridicamente perseguidos por isso. Para esse autor, são vários os momentos que, espalhados em diferentes contextos e momentos na história, demonstram que a intolerância não deve ser exercida, mas sim a tolerância ser colocada em prática, haja vista que é através dela que os homens serão capazes de alcançar o esclarecimento ${ }^{4}$ (TITO, 2021).

Defendia, portanto, que todos os homens fossem considerados como irmãos, algo que chamou a atenção por compreender como sendo óbvio em uma doutrina cristã, em que nesta uns devem tolerar aos outros e, dessa maneira, inclusos aqueles que professem outras fés. A sua obra, que, como o próprio nome diz, refere-se a um Tratado sobre a tolerância, se constituiria, assim, em uma espécie de petição apresentada em nome de toda a humanidade ao

\footnotetext{
${ }^{4}$ Vale lembrar que Voltaire é considerado um dos grandes representantes do Movimento Iluminista na França, tendo defendido que seria a razão o melhor caminho para que o esclarecimento fosse atingido.
} 
poder e à prudência, buscando com isso semear "um grão que poderá um dia produzir uma colheita" (VOLTAIRE, 2017, p. 137).

O autor então deixa bastante claro no decorrer de seu texto que a tolerância traz muito mais benefícios aos indivíduos do que a intolerância, tendo destacado como tantos acontecimentos ao longo da história, marcada por diversas guerras e perseguições, comprovam os seus argumentos. Devido a isso, entendeu que "o direito da intolerância é, portanto, absurdo e bárbaro; é o direito dos tigres, e realmente horrível, porque os tigres não dilaceram senão para comer, enquanto nós nos dilaceramos por causa de alguns parágrafos" (VOLTAIRE, 2017, p. 42).

É nítido da leitura do autor que ele foi influenciado pelo contexto no qual viveu, de tantos conflitos ligados a questões religiosas, algo que também percebemos na Carta de John Locke. Ainda, da mesma forma como nesse último, em Voltaire também é possível identificar uma crítica à censura no sentido de que essa não está em consonância com aquilo que a religião significa verdadeiramente, ou menos que ela deveria significar. Tanto o é que o filósofo francês destaca que "se a perseguição contra aqueles com quem discutimos fosse uma ação santa, é o caso de reconhecer que aquele que tivesse matado o maior número de hereges seria o maior santo no paraíso" (VOLTAIRE, 2017, p. 73).

Nesse sentido, demonstrando seu argumento, em um dos últimos capítulos de seu Tratado ele apresenta uma defesa pela tolerância universal e destaca não considerar "necessária uma grande arte, uma eloquência rebuscada para provar que os cristãos devem se tolerar uns aos outros" (VOLTAIRE, 2017, p. 125), mas que, em realidade, o que é necessário é que consideremos a todos enquanto irmãos, mesmo aqueles com os quais nos aparente impossível fazermos isso, como seria o caso de um judeu, ele exemplifica, afinal, "não somos todos filhos do mesmo pai e criaturas do mesmo Deus?" (VOLTAIRE, 2017, p. 125).

Através disso podemos perceber que o que Voltaire se propõe a fazer por meio de seu texto é demonstrar que a liberdade religiosa deve ser garantida para todos e, assim, haver um exercício de tolerância para com os indivíduos. Utilizando como pano de fundo o drama que envolve a família Calas e a morte de dois de seus membros, ele demonstra que se tivesse havido tolerância para com eles, então essas mortes poderiam ter sido evitadas, colocando, assim, a culpa desses eventos na intolerância religiosa (VOLTAIRE, 2017).

A partir disso, podemos perceber que esses dois textos desenvolvidos nos séculos XVII e XVIII foram muito importantes para que, como argumentos pela tolerância religiosa, 
assentassem o terreno no qual a liberdade de expressão viria a fixar suas raízes. Naquele novo contexto, em uma sociedade moderna com diferentes concepções emergindo, a tolerância assumiu um papel de destaque para a formação política destas. Tendo possibilitado que as pessoas, tão livres quanto egoístas e independentes, fossem capazes de conviver em sociedade sem que, para isso, precisassem renunciar às suas individualidades (ASSAF, 2019).

\section{John Milton e John Stuart Mill: a crítica a censura prévia e o princípio do dano}

Pouco antes dos Tratados sobre a tolerância escritos por Locke e Voltaire, no ano de 1644, o filósofo e poeta inglês John Milton publicou o seu discurso direcionado ao Parlamento Inglês, o qual chamou de Areopagítica". Esse é "considerado por muitos a primeira obra que se dedicou especialmente ao tema da liberdade de imprensa" (ASSAF, 2019, p. 22). Milton estava preocupado com as consequências que poderiam ser trazidas pelo retorno de uma lei que impunha a censura prévia com o objetivo de evitar a publicação de livros considerados difamatórios à religião e ao governo ${ }^{6}$ (MILTON, 1999).

Por isso, em seu discurso o objetivo era criticar a imposição de tal censura, aplicada previamente pelos censores. No entanto, foi apenas nessa que ele se concentrou, eis que no que se refere a possibilidade de imposição de restrições posteriormente, não via necessidade de oposição, pois entendia que em alguns isso seria tanto possível, como necessário. Assim, em relação a Ordenação de licença de 1643, que objetivava aplicar a censura prévia, obrigando que todo e qualquer material escrito necessitasse para a sua publicação de autorização e registro, o autor a via como ineficaz para os objetivos pretendidos e que, em realidade, uma atitude como essa serviria para desestimular todo e qualquer estudo, dificultando, ou até mesmo impedindo, descobertas que poderiam vir a ser alcançadas por meio desses (MILTON, 1999).

\footnotetext{
${ }^{5}$ Conforme Felipe Fortuna (1999, p. 15) no Prefácio à obra publicada no Brasil pela Topbooks em 1999, “o título do panfleto faz referência explícita ao Areopagiticus do orador ateniense Isócrates (escrito provavelmente em 355 a.C.). Ironicamente, Isócrates denuncia em seu discurso político o excesso de liberdade usufruído pelos cidadãos de Atenas e prega o retorno a uma democracia em que só poderiam ser eleitos os cidadãos mais qualificados, o que acabaria constituindo uma aristocracia. $\mathrm{O}$ orador pedia, enfim, que fosse restaurado o Conselho do Areópago, que no passado exercera poderes ilimitados de guardião das leis, supervisor da educação dos jovens, entre outros. Em seu discurso, porém, John Milton fala para o seu areópago, criticando uma decisão". Nota-se aí a inteligência de Milton ao escolher o nome de sua obra.

${ }^{6}$ Três anos antes, em 1641, essa havia sido abandonada por ser considerada tirânica e ilegal. Não obstante, em 14 de junho de 1643, foi promulgada a "Parliamentary Ordinance for Printing" (Ordenação de licença de 1643), responsável por tornar obrigatório que qualquer manuscrito fosse submetido à avaliação estatal, para que essa decidisse pela autorização ou não da publicação.
} 
Para ele, um livro, antes de "vir ao mundo", não deveria ser submetido a um júri, pois não havia justificativas sólidas para que isso pudesse ser feito. Conforme o autor destaca em passagem de seu discurso:

O conhecimento não pode corromper, nem, por conseguinte, os livros, se a vontade e a consciência não se corromperem. Porque os livros são como as carnes e viandas: algumas de boa qualidade, algumas de má qualidade. E, no entanto, Deus, naquela visão canônica, declara sem dissimulação: "Levanta-te, Pedro, imola e come", deixando a escolha à discrição de cada um. Alimentos saudáveis pouco diferem de alimentos estragados no mal que fazem para um estômago doente. Da mesma forma, bons livros para uma mente pervertida constituem oportunidades para o mal. Comida ruim não constitui bom alimento por mais bem preparada que seja (MILTON, 1999, p. 87).

Podemos perceber através desse trecho que o autor entende que de nada adiantaria a aplicação da censura prévia sobre os livros tidos como "maus", dado que mesmo os alegadamente "bons" podem ser convertidos em algo ruim quando assim desejam aqueles que deles fazem uso. Nesse sentido, assim como Voltaire viria a fazer posteriormente, defendia que os homens fizessem uso da razão, sendo essa um dom que os permite definirem por si mesmos os cursos e preceitos de suas vidas (MILTON, 1999).

Logo, os livros que o Parlamento Inglês desejava ver censurados, acreditando serem difamatórios e/ou promíscuos, poderiam se constituir em importantes fontes de conhecimento, que auxiliassem os homens o encontro com a verdade e o abandono do erro e da falsidade. Para tanto, o conhecimento se faz necessário à formação da virtude humana, abrindo espaço para que o erro seja escrutinado e a verdade confirmada, algo para o qual a leitura de toda e qualquer espécie de tratados se faz necessária, com a possibilidade de que os mais diversos argumentos sejam ouvidos e ponderados (MILTON, 1999).

Se os homens letrados são os primeiros beneficiários dos livros e também os propagadores do vício e do erro, como confiar nos censores, a não ser que se lhes atribua, ou que eles mesmos se arroguem, por cima da cabeça dos demais na terra, a graça da infalibilidade e da incorruptibilidade? E mais: se é verdade que um sábio, como um bom garimpeiro, pode encontrar outro em qualquer escória de livro; e que um tolo será um tolo com o melhor dos livros ou sem livro algum, não há razão para privarmos o sábio de um excedente de cultura no afã de impedir que o tolo também o receba, já que não haverá constrangimento para a sua tolice. Se fosse necessário manter longe do tolo o que é impróprio para sua leitura, deveríamos, na opinião não só de Aristóteles, mas também de Salomão, e do nosso Salvador, recusar-lhe os bons preceitos e, em consequência, o acesso aos bons livros. Pois é certo que um sábio fará melhor uso de um panfleto ruim do que qualquer tolo das Escrituras Sagradas (MILTON, 1999, p. 99 e 101).

Aqui é possível perceber que para Milton (1999) a razão significa a liberdade de escolher, isto é, razão e escolha são como sinônimos. Por isso, por mais que os parlamentares nela confiem, a Ordenação por eles imposta não teria como alcançar os fins com ela 
almejados, pois os censores não são homens de qualidades incomuns (as quais deveriam ter, pois que estariam na função de determinar sobre a morte ou a vida de livros). Aqueles que fossem indicados para tal tarefa não poderiam, ao decidir o que é ou não aceitável, cometer erros mesquinhos, sendo injustos.

A Ordenação, ainda que se proponha a algo diverso disso, não poderia evitar tal resultado, de modo que ela não só se revelaria incapaz de fazer qualquer bem para os indivíduos, com ainda acabaria por causar-lhes muitos prejuízos. Isso porque essa representaria "um grande desencorajamento e uma afronta inimaginável ao saber e aos sábios" (MILTON, 1999, p. 119). O conhecimento, portanto, enquanto um produto vistoriado, ficaria sujeito à uma espécie de controle de qualidade. Por isso, o melhor a ser feito é deixar que esses conteúdos sejam livres (ao menos previamente, destaca-se), eis que é a liberdade que nutre os grandes talentos.

Em síntese, o que Milton buscou demonstrar por meio de seu discurso é que a liberdade é sempre a melhor solução e que somente através dela há a possibilidade de que tais materiais que se deseja proibir sejam refutados, tendo chamado a refutação de "melhor e mais eficaz das proibições” (MILTON, 1999, p. 173). Esse é um argumento que anos depois, já no século XIX, seria trabalhado por John Stuart Mill, um dos mais importantes e influentes filósofos a se dedicar ao tema da liberdade de expressão e cuja teoria continua ocupar lugar de destaque para os problemas que envolvem esse direito ainda no século XXI (TITO, 2021).

Em 1859 ele publicou o seu ensaio On Liberty (Sobre a liberdade), no qual defende a liberdade de manifestação do pensamento para todos os cidadãos, acreditando ser esse não só o melhor, mas também o único, caminho para que o conhecimento seja adquirido e a verdade alcançada. Esse autor advogou pela mais ampla liberdade de expressão, defendendo a tese (e vale lembrar que ele foi o primeiro a fazer isso abertamente) de que qualquer opinião deveria ter a possibilidade de circular livremente na sociedade, sem que o Estado, ou uma maioria de que as ideias são majoritariamente aceitas, pudesse nisso intervir (MILL, 2019).

Dada a sua importância, como mencionado, a obra exerce influência até hoje, de modo que "qualquer debate contemporâneo de liberdade de expressão deve passar necessariamente por Mill" (FADEL, 2018, p. 3). A sua obra representa "um marco na filosofia moderna e inaugura uma nova fase do pensamento liberal, desde a forma como o autor enxerga o direito à liberdade aos limites legítimos que estipula ao seu exercício" (FADEL, 2018, p. 13). 
Uma das principais preocupações do autor era aquilo que chamou de "tirania da maioria", que é representada por uma parcela da sociedade que, estando em maioria numerosa, se arroga o papel de oprimir os demais que possuam opiniões distintas das suas. É necessário que se tome cuidado contra esse tipo de abuso de poder. Da mesma maneira, aquelas arbitrariedades que são exercidas por parte do próprio Poder/Estado também deveriam ser evitadas, pois que, segundo o autor, uma nova realidade surgia e atitudes nesse sentido deveriam ficar no passado (MILL, 2019).

No liberalismo milliano o foco reside nos indivíduos, tanto como seres individuais, para o bem de cada um deles, mas também em um sentido mais abrangente, pertinente a sociedade como um todo (MILL, 2019). Isso se dá pelo fato de ter o regime democrático ganhando espaço entre os países e se tornado o modelo político no mundo ocidental, fazendo com que surgisse a necessidade de criação de mecanismos que pudessem auxiliar no controle das paixões da maioria, algo que se tornou a inquietação de diversos autores modernos, dentre eles Mill (FADEL, 2018).

Nesse sentido, contra o arbítrio que venha a ser exercido pelo Estado ou pelos cidadãos uns para com os outros, surge a interpretação de que é a liberdade que representa um direito individual a ser protegido. Para isso, Mill (2019) defende a tese de que todas as ideias devem poder circular livremente na sociedade, por mais absurdas ou impossíveis que elas aparentem ser, pois somente dessa maneira ela poderia ser confrontada, discutida, refutada e, se assim compreendido, trocada pela verdade. Isso significa que somente quando as pessoas possuem a liberdade para apresentarem ao mundo as suas opiniões é que elas terão a oportunidade de trocar o erro pela verdade.

Nota-se com isso que a teoria milliana tem como foco o alcance da verdade, uma visão consequencialista da liberdade de expressão. Não obstante, a sua defesa desse direito é revolucionária e, seja com o intuito de criticá-la ou não, é aquela que continua a exercer maior impacto nas discussões até hoje desenvolvidas sobre as teorias da liberdade de expressão. Isso se dá também porque buscando compreender onde residiriam os limites desse direito, podendo estabelecê-lo de modo legítimo, o autor apontou que a única razão pela qual essa liberdade poderia ser restringida é quando se tornasse um incitamento à violência (MILL, 2019).

Portanto, em Mill, o limite legítimo da liberdade de expressão reside no dano, daí a denominação de "princípio do dano", significando que os indivíduos sejam livres para que 
realizem os seus desejos, desde que, ao fazê-lo, não acabem por prejudicar outras pessoas (MILL, 2019). Com esse princípio, aplicado conforme por ele proposto, o autor deixa bastante claro que só poderia haver intervenção sob a liberdade das pessoas para que vivam as suas vidas como elas quiserem nos casos nos quais elas imponham danos umas as outras (WARBURTON, 2009).

Sobre isso, nas palavras do autor:

O objetivo deste ensaio é defender um princípio muito simples, como único habilitado a reger de modo absoluto as relações da sociedade com o indivíduo por meio da obrigatoriedade e do controle, quer o meio usado seja a força física segundo as penas da lei ou a coerção moral da opinião pública. Este princípio é o de que o único fim pelo qual a humanidade está autorizada, individual ou coletivamente, a interferir na liberdade de ação de qualquer um de seus integrantes é a autodefesa. Pois o único propósito para o qual o poder pode ser legitimamente exercido sobre qualquer membro de uma comunidade civilizada, contra sua vontade, é evitar dano aos outros. Seu próprio bem, físico ou moral, não é justificativa suficiente. O indivíduo não pode ser legitimamente obrigado a fazer ou deixar de fazer alguma coisa porque assim seria melhor para ele, porque o faria mais feliz, porque fazer tal coisa seria, na opinião dos outros, sensato ou mesmo correto. Essas são boas razões para admoestá-lo, para argumentar com ele, para persuadi-lo, para pedir-lhe, mas não para obrigá-lo nem para lhe infligir qualquer mal caso aja de outra maneira. Para que isso se justifique, é preciso que a conduta da qual se deseja dissuadi-lo seja deliberadamente destinada a causar mal a outra pessoa. A única parte da conduta de uma pessoa pela qual ela é responsável perante a sociedade é a que concerne ao outro. Na parte que concerne apenas a si mesma, sua independência é, de direito, absoluta. Sobre si mesmo, sobre seu corpo e sua mente, o indivíduo é soberano (MILL, 2019, p. 22-23).

Com isso, fica evidente que para a teoria milliana a liberdade de expressão é um direito de suma importância e apenas em tal situação excepcional seria possível restringi-la. Além disso, essa liberdade possibilita que o espírito de debates entre os indivíduos sobreviva, o que permite que esses discutam verdades tomadas como absolutas e, assim, as confirmem ou mudem de ideia (MEDRADO, 2019). Isso aumenta a probabilidade de que um melhor resultado seja alcançado, isto é, a eliminação do erro (WARBURTON, 2009).

O Ensaio de Mill influenciou muitos autores, dentre os quais juízes da Suprema Corte norte-americana, que a adotaram em suas decisões e mudaram para sempre aquela compreensão que era até então dada a esse direito naquele cenário. Em relação a isso, a moderna doutrina da liberdade de expressão tem a sua origem nos Estados Unidos, que, com a sua Primeira Emenda, protege essa liberdade com amplitude, a interpretando como indispensável a manutenção do regime democrático. Dessa maneira, avançando na linha do tempo e alterando o contexto de discussão, nos dedicaremos na sequência a compreender essa nova realidade na qual a liberdade de expressão se firmou (LEWIS, 2007). 


\section{A moderna doutrina da liberdade de expressão: a Primeira Emenda da Constituição norte-americana e os tratados internacionais}

Conforme acima destacado, é nos Estados Unidos que se inicia a moderna doutrina da liberdade de expressão, o que ocorreu por meio de um longo processo de alteração na forma como a sua legislação passou a ser interpretada. Sobre isso, foi especialmente através dos juízes da Suprema Corte norte-americana, como Oliver W. Holmes Jr. (1841-1935) e Louis Brandeis (1856-1941), que tais mudanças ocorreram e foram se consolidando. Esses juízes, principalmente entre os anos de 1919 e 1929, representaram importantes votos dissidentes em uma série de casos relacionados à Primeira Emenda, sendo os responsáveis por modificar consideravelmente a interpretação que era até então dada a essa liberdade (LEWIS, 2007).

Em relação a isso, "os significados da liberdade de expressão e da liberdade de imprensa não brotam espontaneamente de uma interpretação literal do texto constitucional. Foi somente com o passar dos anos que a jurisprudência americana foi fixando o seu entendimento sobre a real extensão" (MEDRADO, 2019, p. 40) de proteção que deve ser concedida ao discurso, com base naquilo que a Primeira Emenda determina. Isso porque, geralmente, ainda no século XIX a Suprema Corte tinha a tendência de rejeitar as reivindicações sobre liberdade de expressão, por considerá-las um assunto sem grande importância.

No entanto, no século seguinte isso seria modificado, com uma mudança de posicionamento que influenciaria todo o debate da liberdade de expressão até a atualidade (LEWIS, 2007). Sobre isso, “a década de 1930 marcou uma virada na compreensão da liberdade de expressão pela Suprema Corte dos Estados Unidos” (MEDRADO, 2019, p. 49). O que se deu devido a uma série de casos julgados por seus juízes e que, aos poucos, principalmente com os votos dissidentes de Holmes e Brandeis, conforme apontado, foi sendo construída.

Em relação a isso, não é possível aqui abordarmos e analisarmos cada um desses casos, mas cabe destacar que de uma jurisprudência antes menos protetiva e preocupada com a liberdade de expressão, essa se transformou em uma das que mais a protege no mundo todo, servindo de exemplo para muitos dos países que, embora adotem a democracia como regime 


\section{A TRAJETÓRIA HISTÓRICA DA LIBERDADE DE EXPRESSÃO: SUA IMPORTÂNCIA PARA A LEGITIMIDADE DA DEMOCRACIA}

político, ainda lidam com inúmeros problemas para, de fato, a tornarem legítima. Nesse contexto, a liberdade de expressão de faz indispensável, pois, conforme interpretado por um de seus maiores defensores, Ronald Dworkin, não há que se falar em democracia se não for garantido para todos os cidadãos o direito para que se expressem livremente acerca dos mais distintos assuntos, sejam eles tomados como relevantes ou inconvenientes (DWORKIN, 2019).

Nesse cenário de construção da liberdade de expressão como um direito fundamental que deve ser assegurado sem diferenciações para todas as pessoas, há que se falar da importância dos tratados internacionais. Isso porque diante das tantas mudanças ocorridas no mundo, causadas pelos vários eventos históricos, dentre eles a Segunda Guerra Mundial, tornou-se evidente que eram necessárias uma série de modificações na forma como o Direito era até então compreendido, havendo urgência em reconhecer os indivíduos enquanto seres humanos dotados de dignidade, com um reconhecimento e proteção disso (BARRETTO, 2013).

Em tais documentos foram assegurados diversos dos direitos que, juntos, compõem essa dignidade dos cidadãos. Dentre eles está a liberdade de expressão, que é assegurada em cada um desses documentos em âmbito regional e internacional, responsáveis por juntos constituírem os Sistemas Internacionais e Regionais de Proteção dos Direitos Humanos. Observadas as especificidades que envolvem cada um deles, nota-se que em comum todos eles colocam a liberdade de expressão como um direito indispensável a ser garantido para todos, sem diferenciações.

Compondo o Sistema Regional há o Europeu, o Americano e o Africano, em que os seus documentos, a Convenção Europeia dos Direitos Humanos, a Convenção Americana dos Direitos Humanos - CADH e Carta Africana, respectivamente, possuem todos eles dispositivos que tratam da liberdade de expressão. Na primeira delas, a Convenção Europeia dos Direitos Humanos, é um dos mais importantes acordos da comunidade europeia e traz em seu art. $9^{\circ}$ o direito à liberdade de pensamento, consciência e religião, prevendo que qualquer pessoa tem direito a essas, não podendo sofrer restrições além daquelas que a própria Convenção já prevê por compreendê-las como necessárias. Além desse dispositivo, o seu art. $10^{\circ}$ estabelece de modo específico o direito à liberdade de expressão, não podendo haver ingerência das autoridades públicas sobre o seu exercício (EUROPEAN CONVENTION ON HUMAN RIGHTS, 1950). 
Já o segundo desses documentos, a $\mathrm{CADH}$, com a qual o Brasil se compromete, tendo a ela aderido em 1992, há o propósito, dentre outros, de consolidação em todo o continente americano de um regime de liberdade pessoal. Para tanto, é o seu art. 13 que traz as liberdades de pensamento e de expressão, garantindo-as para todos os cidadãos, os quais são livres para exercê-las em meio verbal, escrito, impresso ou artístico. A CADH veda a aplicação de censura prévia e determina que as pessoas só poderão ser responsabilizadas por eventual excesso no exercício dessas liberdades posteriormente ao ocorrido e desde que tal responsabilização esteja expressamente fixada por lei (BRASIL, 1992).

A Carta Africana dos Direitos Humanos e dos Povos, que também pode ser referida como Carta de Banjul, foi aprovada em 1981 e entrou em vigor cinco anos depois, em 1986, sendo o mais recente desses documentos a constituírem os sistemas regionais. A liberdade de expressão nesta se encontra prevista nos art. $8^{\circ}$ e $9^{\circ}$, segundo os quais é assegurado para todos os cidadãos o direito à liberdade de consciência, profissional e religiosa, podendo ser exercidas sem constrangimentos ou restrições, salvo por questões determinadas como de ordem pública. A de expressão (art. $9^{\circ}$ ) dá para todos o direito de se informarem, exprimirem e difundirem suas opiniões (BANJUL CHARTER, 1981).

A partir de tais previsões podemos perceber que a liberdade de expressão é hoje um direito que possui o status de direito humano protegido em caráter universal, tendo assim se consagrado em razão dos tratados internacionais que aqui foram mencionados e pelos eventos que, no transcorrer da história, desencadearam a sua formação (TITO, 2021). Por isso, é possível compreendermos que a consagração da liberdade de expressão "caminha lado a lado com a afirmação histórica dos direitos humanos, sendo, também, cerne do Estado de Direito" (SÁ, 2020, p. 27).

Cabe ainda destacar que no que se refere ao contexto brasileiro, no qual a presente pesquisa se insere, a liberdade de expressão sempre foi assegurada por todas as Constituições vigentes, mesmo durante períodos ditatoriais. O que as diferenciava era, em maior ou menor medida, a sua colocação em prática, posto que em diversos momentos, especialmente durante as ditaduras brasileiras, embora a liberdade de expressão estivesse prevista no texto constitucional isso não significava que, de fato, havia possibilidade aos cidadãos para que a exercessem livremente (TITO, 2021). No Brasil, foi somente a partir da Constituição Federal de 1988 que a liberdade de expressão se consagrou com o status de garantia fundamental, 
algo que até então, não obstante as previsões anteriores, ainda não havia recebido (BRASIL, 1988).

\section{Considerações finais}

A presente pesquisa objetivou analisar a história da liberdade de expressão, tendo em vista a importância que hoje essa possui para a legitimação e manutenção do Estado Democrático de Direito. Para tanto, foram delineados alguns dos principais autores e momentos históricos que são os responsáveis para que assim essa garantia se consolidasse. No entanto, tendo em vista a extensa produção bibliográfica existente acerca desse tema, assume ser inviável a realização de uma reconstrução histórica que delineie sobre todos eles. Ainda assim, diante do objetivo proposto, foi possível nos debruçarmos sobre aqueles que foram os responsáveis pela compreensão que hoje se tem desse direito.

Com isso, vimos que as discussões a respeito do princípio da tolerância foram as responsáveis por dar origem aquilo que, posteriormente, se transformaria na defesa pela liberdade de expressão dos cidadãos. Compreender acerca desse princípio foi algo que se tornou importante a partir do advento das sociedades modernas, as quais, marcadas pelo pluralismo, precisavam encontrar uma forma a partir da qual as distintas concepções de mundo e de vida conseguissem coexistir. Nesse momento, destacam-se autores como John Locke e Voltaire, ambos inspirados por um contexto de perseguições e intolerância religiosa tentaram trazer argumentos em favor da tolerância e do uso da razão.

Restou também demonstrado que ainda em 1644, no ambiente inglês e diante da tentativa de imposição da censura prévia, John Milton foi um autor que se destacou por lutar contra tal possibilidade. Discursando perante o Parlamento Inglês, ele apontou para a inutilidade da censura, que, ainda que aplicada, não obteria os fins pretendidos, isto é, de impedir a circulação de livros vistos como "maus", deixando apenas os "bons" virem à público. Isso porque mesmo os manuscritos alegadamente "bons" podem ser convertidos em algo ruim quando assim desejam aqueles que deles fazem uso.

Isso demonstra que, assim como posteriormente entenderia Voltaire, os homens devem fazer uso da razão, sendo por ela guiados, haja vista ser ela um dom que os permite definirem por si mesmos os cursos e preceitos de suas vidas. Em sentido semelhante, no século XIX, um outro autor inglês contribuiria de modo extremamente importante para as 
discussões sobre a liberdade de expressão. Esse foi o filósofo John Stuart Mill, até hoje considerado um dos mais importantes autores a se dedicarem ao tema. Mill formulou o chamado "princípio do dano", de acordo com o qual o limite legítimo da liberdade de expressão reside no dano que essa possa causar para terceiros e, somente nesses casos, podendo sofrer restrições.

A sua formulação ganhou espaço nas discussões ocorridas na Suprema Corte norteamericana, considerada uma espécie de berço da moderna doutrina da liberdade de expressão. Nesse ambiente, a partir das interpretações realizadas da Primeira Emenda e com os casos que chegaram aos seus juízes, foi sendo construída uma jurisprudência bastante favorável desse direito, que assumiu uma posição extremamente importante para a manutenção do Estado de Direito. Da mesma forma, foram abordados os documentos internacionais responsáveis por demonstrarem que a liberdade de expressão se consagra juntamente a afirmação histórica dos direitos humanos.

Todo esse processo de reconstrução histórica do direito à liberdade de expressão se revela uma tarefa de grande relevância por confirmar que o seu surgimento advém de um extenso processo que nos últimos séculos auxiliou a construir e consolidar aquilo que hoje conhecemos como Estado Democrático de Direito. Nesse regime político, a liberdade de expressão se constitui em um elemento essencial que lhe dá legitimidade, pois só é possível entendermos que a democracia é legítima quando há nesta a garantia de liberdade para que os cidadãos se manifestem. Assim, nas diversas variantes que envolvem esse direito, há a compreensão comum de que ele se refere, para as sociedades contemporâneas, um elemento indispensável.

\section{Referências bibliográficas}

AFRICAN (BANJUL) CHARTER ON HUMAN AND PEOPLE'S RIGHTS. Adopted 27 June 1981, OAU Doc. CAB/LEG/67/3 rev. 5, 21 I.L.M. 58 (1982), entered into force 21 October 1986. Disponível em: https://files.ondemandhosting.info/data/www.humanrights.org/files/5.African\%20Charter\%20 of\%20Human\%20and\%20People's\%20Rights.pdf Acesso em: 08 set. 2021.

ASSAF, Matheus. Liberdade de expressão e discurso de ódio: Por que devemos tolerar ideias odiosas? Belo Horizonte: Dialética, 2019.

BARRETTO, Vicente de Paulo. O Fetiche dos Direitos Humanos e outros Temas. 2. ed. rev. e ampl. Porto Alegre: Livraria do Advogado, 2013. 
BRASIL. Constituição (1988). Constituição da República Federativa do Brasil. Brasília, DF, Senado, 1988. Disponível em:

http://www.planalto.gov.br/ccivil_03/constituicao/constituicao.htm Acesso em: 09 set. 2021.

BRASIL. Decreto $n^{\circ}$ 678, de 6 de novembro de 1992. Promulga a Convenção Americana Sobre Direitos Humanos, Pacto de São José da Costa Rica, de 22 de novembro de 1969. Brasília, 6 de novembro de 1992. Disponível em: http://www.planalto.gov.br/ccivil_03/decreto/d0678.htm Acesso em: 07 set. 2021.

DWORKIN, Ronald. $O$ direito da liberdade: a leitura moral da constituição norte-americana. Trad. Marcelo Brandão Cipolla. 2. ed. São Paulo: Martins Fontes, 2019.

EUROPEAN CONVENTION ON HUMAN RIGHTS. Members of the Council of Europe. Rome, 04 nov. 1950. Disponível em:

https://www.echr.coe.int/Documents/Convention ENG.pdf Acesso em: 08 set. 2021.

FADEL, Anna Laura Maneschy. O discurso de ódio é um limite legítimo ao exercício da liberdade de expressão? Uma análise das teorias de Ronald Dworkin e Jeremy Waldron a partir da herança do liberalismo de John Stuart Mill. Rio de Janeiro: Lumen Juris, 2018.

GALUPPO, Marcelo Campos. Democracia e Tolerância. In: BITTAR, Eduardo Carlos Bianca; SOARES, Fabiana de Menezes (Org.). Filosofia do Direito: novos cenários, velhas questões. Barueri: Manole, 2004, p. 221-236.

LEWIS, Anthony. Freedom for the Thought That We Hate: A biography of the first amendment. New York: Basic Books, 2007.

LOCKE, John. Carta sobre a tolerância. Trad. Adail Sobral. Petrópolis: Vozes, 2019.

MEDRADO, Vitor Amaral. A liberdade de expressão e a justiça brasileira: tolerância, discurso de ódio e democracia. 2. ed., rev. e ampl. Belo Horizonte: Dialética, 2019.

MILL, John Stuart. Sobre a liberdade. Trad. Denise Bottmann. Porto Alegre: L\&PM, 2019.

MILTON, John. Areopagítica: Discurso pela liberdade de imprensa ao Parlamento da Inglaterra. Trad. Felipe Fortuna. Rio de Janeiro: Topbooks, 1999.

SÁ, Mariana Oliveira de. O discurso de ódio, o silêncio e a violência: lidando com ideias odiosas. Belo Horizonte: Dialética, 2020.

TITO, Bianca. $O$ direito à liberdade de expressão: o humor no Estado Democrático de Direito. Belo Horizonte: Dialética, 2021.

VOLTAIRE. Tratado sobre a tolerância. Trad. Antônio Geraldo da Silva. São Paulo: Lafonte, 2017.

WARBURTON, Nigel. Free speech: a very short introduction. New York: Oxford University Press, 2009. 